\title{
Cold exposure as a natural tool to treat obesity in humans
}

\begin{abstract}
Treating obesity has become very challenging despite behavioral, pharmacological and surgical approaches are being available. In recent years, especially after confirming the presence of functionally active brown fat cells in the adult humans, exposing obese individuals to cold environment has attracted a lot of attention to treat obesity using it as a simple and physiological means. Brown fat with two major roles in energy regulation and thermoregulation is a unique tissue present in almost all mammalian species. It is distributed diffusely in the body as small depots. It works on the principle of activation of brown fat during such cold exposure via the sympathetic nerves mediated by beta- 3 adrenergic receptors in those cells. Such activation results in regulatory heat production in the brown fat by burning the energy substrates as heat rather than generating energy and storing it as fat. With the current advancement in the knowledge of adipose tissue in general and brown fat in particular, the aim of this article is to provide a clear insight into various aspects of brown fat function control that could be used as a simple treatment of obesity.
\end{abstract}

Keywords: white adipose tissue, brown fat, thermogenesis, obesity
Volume 7 Issue 2 - 2017

\author{
Muralidhara DV \\ FR Muller Research Center, India
}

Correspondence: Muralidhara DV, FR Muller Medical Research Center, Kankanady, Mangalore - 575002, India, Email diviem@yahoo.com

Received: June 23, 2017 | Published: August 22, 2017

\section{Introduction}

Human obesity is a serious health issue as it affects cardiovascular, respiratory, reproductive, digestive, musculoskeletal and other systems of the human body along with metabolic dysfunctions such as lipotoxicity and diabetes mellitus in addition to development of various types of cancers and has drawn the attention worldwide to understand its pathophysiology and treatment. ${ }^{1}$ Obesity is considered as a disease of hedonistic life style and also as a mild inflammatory state associated with an increase in certain adipokines such as tumor necrosis factor- $\alpha$ (TNF- $\alpha$ ), interleukins $1 \alpha$ and 6 (IL- $1 \alpha$, IL-6) secreted by white adipose tissue (WAT). Innumerable secretions from WAT (adipokines) have been recognized that play a vital part in obesity and its disorders. Several factors such as transcriptional, hormonal and signaling regulators that govern the thermogenic functions of brown adipose tissue (BAT) have given more insights to the understanding of its role in obesity. Based on these findings, strong suggestions have been made for treating obesity specially by targeting the brown fat as it plays a key role in energy expenditure through regulatory thermogenesis. The aim and objective of this communication is to provide in a nutshell the treatment for obesity with an emphasis on cold exposure as a tool to treat obesity via brown fat activation that has a key role in body weight control and body temperature regulation especially in the new born.

Physiologically, obesity results from a disparity in energy balance either by an increased energy intake and/or by a decrease in energy

Table I Biological effects of some adipokines. ${ }^{5,7,8}$ expenditure. ${ }^{2}$ Obesity is usually attributed to poor life style practices that includes unhealthy food consumption, increased caloric intakes and altered diet composition, sedentary life, particularly reduced occupational physical activity or without much physical activities or both. ${ }^{3}$ The energy expenditure components include resting/basal metabolic rate (RMR/BMR), regulatory/adaptive thermogenesis and the energy spent on physical activity. ${ }^{3}$

As referred earlier, obesity though is a mismatch between energy intake and energy output, it results basically from dysfunctions of both WAT and BAT. Adipose tissue, particularly WAT that contributes to about $20-25 \%$ of body weight is now recognised as more than just a passive fat store house because of its endocrine secretions and is recognized as the biggest endocrine gland in humans. ${ }^{4,5}$ Adipose tissue physiology has attained greater importance in research in the last two decades to address problems associated with obesity, diabetes mellitus, insulin resistance, cancer and metabolic syndrome etc. ${ }^{6}$ WAT secretes more than 100 compounds called as adipokines. The locations of adipose tissue (subcutaneous or visceral) itself affect the secretion profile of adipokines indicating a high degree of heterogeneity and thereby contributing to disease processes. Such findings may suggest that adipose tissue is perhaps a group of similar but unique endocrine organs. ${ }^{7}$ Some of these secretions act through autocrine, paracrine and endocrine routes. Many functions such as the metabolic, immunologic, energy balance, cardiovascular, inflammatory and hormonal signaling have been ascribed to these adipokines. ${ }^{8}$ Major physiological roles of a few important adipokines are given in Table 1 .

\begin{tabular}{ll}
\hline Adipokines & Role \\
\hline Leptin, Interleukin-I and 6. (IL-I,6) & Energy balance, food intake, reproduction and body weight control. \\
Adiponectin, Resistin, Adiponutrin,Visfatin, Omentin. & Glucose homeostasis. \\
Tumor necrotic factor- $\alpha$, IL-6, Resistin. & Insulin resistance \\
\hline
\end{tabular}


Table Continued....

\begin{tabular}{|c|c|}
\hline Adipokines & Role \\
\hline Retinol-binding protein, Cholesterol ester transfer protein. & Lipid metabolism \\
\hline Angiotensinogen. & Hypertension \\
\hline Resistin. & Increases insulin resistance and contributes to cardiovascular diseases. \\
\hline TNF- $\alpha$, IL-6 & $\begin{array}{l}\text { Lipolytic, increases energy consumption, reduces sensitivity to insulin, has } \\
\text { immunological, pro/anti-inflammatory effects. }\end{array}$ \\
\hline Vascular endothelial growth factor, Angiotensinogen, Monobutyrin & Angiogenesis and Vascular homeostasis \\
\hline Plasminogen activator inhibitor-I & Fibrinolytic system \\
\hline Transforming growth factor- $\beta$ & $\begin{array}{l}\text { Regulates proliferation of preadipocytes and differentiation of WAT, development and } \\
\text { apoptosis of adipocytes. }\end{array}$ \\
\hline Insulin like growth factor-I, Hepatocyte growth factor. & Stimulates proliferation development and differentiation of adipocytes. \\
\hline Macrophage migrating inhibitory factor. & Immunoregulator with paracrine action in WAT and pro-inflammatory. \\
\hline Apelin & $\begin{array}{l}\text { Biological actions not very clear yet but are related to reducing the body's energy } \\
\text { stores. }\end{array}$ \\
\hline Vaspin & A biomarker for inflammation and cardiovascular diseases. \\
\hline Leptin, Adinopectin, ASP,Visfatin, Resistin, Ghrelin & $\begin{array}{l}\text { These adipokines have some role to play in pineal gland function and alcohol } \\
\text { consumption induced obesity }\end{array}$ \\
\hline
\end{tabular}

Overall, majority of the adipokines from WAT affect insulin functions, glucose metabolism and lipid metabolism negatively resulting in the development of metabolic syndrome features such as higher adiposity, hypertension, diabetes mellitus, cardiovascular effects and inflammatory process with other manifestations. ${ }^{8}$ Since obesity, hypertension and diabetes mellitus are closely intertwined, the sequence of events leading obesity to insulin resistance and hypertension could be explained as follows. Adipocyte hypertrophy in obesity leads to adipocyte stress, possibly involving hypoxia that favours the production of chemo-attractants. This further promotes infiltration of macrophages into the adipocytes which may lead to the death of adipocytes. Chronic reabsorption of adipocyte remnants by macrophages is then favoured accompanying a massive production of cytokines by macrophages such as TNFa, resistin, leptin and a decrease in adinopection resulting in reduced insulin sensitivity, endothelial dysregulation leading to atherosclerosis, thrombosis, sodium retention and increased sympathetic activation. ${ }^{9,10}$ These changes will contribute to the development of hypertension and insulin resistance in peripheral tissues.

\section{Brown adipose tissue}

BAT contributes to about $5 \%$ of body weight in infants and less than $2 \%$ in adults. It is usually found mainly in inter-scapular space, nape of the neck, along the great vessels in the thorax and abdomen and other areas embedded with muscles in the neck and other structures. ${ }^{11}$ Microscopically, it is different from the white fat that it is darker in color, smaller in size of 60-80micron, have many fat globules and mitochondria. Its key role is thermogenesis (heat production) that is concerned with body temperature regulation especially in the new born and infants, arousal from hibernation in small mammals, energy regulation and body weight control in adult humans. ${ }^{12}$ This heat production from BAT is sometimes referred to as adaptive thermogenesis or metaboloregulatory thermogenesis that primarily includes nonshivering thermogenesis (NST), diet induced thermogenesis (DIT) and cold induced thermogenesis (CIT). BAT has rich sympathetic nerve supply and blood flow that helps to a large extent in BAT recruitment and stimulation during CIT. ${ }^{13}$ BAT also secretes a few hormones like substances (for example IL-6) called 'batokines' just as the WAT secretes adipokines. ${ }^{14}$ BAT is of two types; i) classical one found in the above mentioned areas and ii) inducible/ brite/beige/recruitable brown fat cells scattered within the WAT depots which can be found under different conditions such as chronic cold exposure, $\beta$-adrenergic receptor agonists treatment or peroxisome proliferator activated receptor gamma (PPAR gamma) treatment or chronic high fat diet feeding. ${ }^{15}$ However, it is important to note that the adipose tissue has the ability of plasticity and trans-differentiation that contributes to the above phenomenon. Physiologically, sympathetic activation is considered the ultimate route of BAT activation in its thermogenic functions. ${ }^{14,16}$ In the BAT mitochondria, inward proton conductance that generates ATP (oxidative phosphorylation) takes place as usual, but in addition there is a second proton conductance that does not generate ATP. This 'short-circuit' conductance depends on a 32-kDa uncoupling protein-1 (UCP1), located in the inner membrane of the mitochondria. This protein causes more heat production by uncoupling of metabolism and generation of ATP. ${ }^{17}$

Recent contributions in BAT research such as the identification of i) active and functional BAT in adult humans, ii) classical and beige/ brite types of BAT cells, iii) a number of regulatory factors involved in the control of BAT development and function and iv) a cross-talk between BAT and other peripheral tissues such as skeletal muscle, liver, heart, gut etc, have generated great interests and hopes in the treatment of obesity and associated co-morbidities. ${ }^{12,18}$ Thus, both WAT and BAT has become the target to explore the pathophysiology of obesity and its related metabolic disturbances.

\section{Control of BAT function}

BAT metabolism is affected by various physiological factors such as age, gender, BMI, body fat levels, hypoxia and most importantly ambient temperature (cold exposure) and other disease conditions such as diabetes mellitus. ${ }^{16,19}$ The factors that regulate BAT development and functions can be broadly divided into

\section{Transcriptional factors}


2. Signaling pathways

3. Endocrine factors
In addition, BAT mediated inter organ networking or cross talks in understanding the functional control of BAT are another interesting facet. More details are available elsewhere ${ }^{12,20-23}$ (Table 2-5).

Table 2 Transcriptional factors

Transcriptional factors. ${ }^{12,20,22,23}$
PPAR $-\gamma$
CCAAT enhancing binding proteins (C/EPB) $\gamma, \beta$ and $\delta$.

Role

Forkhead box C2 (FoxC2).

PPAR- $\gamma$ is a key factor required unconditionally for adipogenesis.

PGC-I $\alpha$

$\mathrm{C} / \mathrm{EBP} \alpha$ is required for WAT formation. C/EBP $\beta$ controls thermogenic gene expression in BAT. Increases mitochondria, thermogenic genes and UCPI. Induces the formation of brite cells in WAT.

Receptor-interacting protein I40 (RIPI40).

A cold inducible transcriptional co-activator of PPAR- $\gamma$. Regulates mitochondrial biogenesis and oxidative metabolism in BAT.

Modulate the activity of PGC-Ia.

PRDI-BF-I-RIZI homologous domain-containing protein 16 (PRDMI6).

Acts as a molecular switch between myocytes and brown adipocytes. Increases the transcriptiona activities of PGC-I $\alpha$ and PPAR- $\gamma$ and the C/EPBs. Promotes brown fat gene expression and mitochondrial biogenesis.

Early B cell factor 2 (EBF2) and microRNAs such as miR-I33 and miR-193b

Influence PRDMI6 activities.

Table 3 Signaling pathways

\begin{tabular}{|c|c|}
\hline Signaling pathways ${ }^{12,24}$ & Role \\
\hline Norepinephrine. & $\begin{array}{l}\text { Influences proliferation of classical brown adipocyte precursors and mediates thermogenic function via } \beta-1 \\
\text { and } \beta-3 \text { adrenergic receptors, respectively. }\end{array}$ \\
\hline Nitric oxide. & Activates cGMP dependent protein kinase in brown adipocytes thereby induces UCPI expression. \\
\hline $\begin{array}{l}\text { Transient receptor potential } \\
\text { vanilloid (TRPV) signaling. }\end{array}$ & $\begin{array}{l}\text { Involves ion channels activated by heat greater than } 430 \mathrm{C} \text { and pungent compounds in chilli peppers, non- } \\
\text { pungent (capsinoids) capsaicin analogs activate BAT thermogenesis in humans and rodents. }\end{array}$ \\
\hline
\end{tabular}

Table 4 Endogeneus hormones

Endogenous hormones ${ }^{25-31}$
Transforming growth factors (TGF), including bone
morphogenetic proteins (BMP).
Myostatin.
Fibroblast growth factors (FGFs), FGF- |9, FGF-2I and
FGF-23.
Irisin.
Cardiac natriuretic peptides (CNP) from atria and
ventricle of the heart (ANP,VNP, respectively) and brain
natriuretic peptides (BNP).
Prostaglandins (PGs) and vascular endothelial growth
factor (VEGF).

\section{Role}

Promote BAT thermogenic functions and increase the energy expenditure and reduce body fat mass. Induces brite cells in WAT.

Negatively regulate BAT differentiation and thermogenesis.

It appears that PPAR-gamma transcriptionally controls FGF-2I and thereby BAT functions

Released by skeletal muscle through increased PGC-I a expression following exercise. Irisin treatment induces a thermogenic gene program in BAT and protects the animals from diet induced obesity.

Regulators of fluid and hemodynamic functions. Cold exposure seems to improve the circulating levels of ANP and BNP and administration of BNP activates the BAT thermogenic functions.

Also plays an important role in cold induced brite cell formation, BAT thermogenesis and energy expenditure.

Table 5 Interorgan network

\begin{tabular}{|c|c|}
\hline Interorgan network $k^{8,12,21,32-34}$ & Role \\
\hline $\begin{array}{l}\text { Norepinephrine produced in the CNS and } \\
\text { by the macrophages in the adipose tissue. }\end{array}$ & Activate the brown fat development and thermogenic function. \\
\hline TGF- $\beta$ from the skeletal muscle. & Negatively controls BAT function. \\
\hline $\begin{array}{l}\text { Cold induced tri-iodothyronine (T3) } \\
\text { secretion and norepinephrine in BAT. }\end{array}$ & $\begin{array}{l}\text { Norpeinephrine via } \beta-3 \text { receptors increases BAT thermogenic functions. High endogenous expression } \\
\text { and activity of intracellular type-2 5'-deiodinase (D2) in BAT increases substantially the intracellular } \\
\text { concentrations of T3 without affecting its circulating concentrations. This increases UCPI which facilitates } \\
\text { BAT thermogenesis. }\end{array}$ \\
\hline Bile acid from liver & Reported to activate D2 in BAT thereby promoting thermogenesis thus acting as an endocrine signaler. \\
\hline
\end{tabular}




\section{Treating obesity}

The management of obesity through lifestyle practices is quite challenging. Several approaches for treating obesity such as diet modification, increasing physical activity levels (behavioral approach), use of weight loss medications (pharmacological approach), exposure to lower ambient temperature/cold environment (physiological approach) as well as surgical procedures in appropriate patients could be considered. ${ }^{35-39}$ Recently, sibutramine and rimonabant (anti-obesity drugs) are withdrawn for safety concerns. ${ }^{38,39}$ and bariatric surgery is only applicable to a sub-group of obese patients. ${ }^{39,40}$ It has been reported that transplantation of BAT corrected type 1 diabetes in immunecompetent mice as was evident by reversal of diabetes symptoms, improved insulin sensitivity, weight regain and normalization of glucose tolerance..$^{41}$ Therefore, it becomes a necessity to identify new and effective therapeutic options for obesity. Increasing energy expenditure through a physiological mechanism appears to be the most logical and a very lucrative one. Animal studies have shown that by activating BAT, triglyceride stores within WAT could be utilized for heat production by modulating adaptive thermogenesis. ${ }^{42}$

As referred before, transcriptional factors such as PRDM16 and other associated co-regulators PGC $-1 \alpha$ and $\mathrm{C}$-terminal binding protein (CtBP1/2) which controls the switch from WAT to BAT are potential targets for the development of obesity related treatments. ${ }^{43,44}$ BAT development and functions are also influenced by several hormonal factors derived from various tissues such as liver, skeletal muscle, heart, and immune cells. BAT in adult humans can be recruited by chronic cold exposure and TRPV1 agonists. The observation that cold exposure stimulates BAT thermogenesis has become very handy when other forms of obesity treatment (behavioral, pharmacological and surgical) have not found much success. ${ }^{12,21,22,32}$ Therefore, cold stimulation is considered as the safest, best and potent activator of BAT as of date compared to $\beta$-agonist or symapthomimetic stimualtions. ${ }^{14,45}$ BAT makes use of carbohydrates and lipids during cold exposure to enhance heat production via $\beta-3$ adrenergic receptor. Experimental findings on cold exposure in BAT research is quite varied and and less standardized. Different cold exposure methods used include air exposure in environmental chambers, water immersion, liquidconditioned suit, water perfused mattress and limb cooling methods on fixed cooling and individualized cooling protocols.

Cold treatment basically consists of exposing subjects at $16^{\circ} \mathrm{C}$ to $19^{\circ} \mathrm{C}$ for 2 hours in a cold room. ${ }^{46}$ Air fans and cooling's vests can be used to achieve the required temperatures. ${ }^{47}$ This type is know as fixed type cooling protocol. While using this protocol, obese subjects may be exposed to an insufficient temperature because of the extra subcutaneous fat that provides better insulation..$^{48}$ Therefore, obese subjects are cold exposed until shivering occurs and then the temperature is set at $1{ }^{\circ} \mathrm{C}-2^{\circ} \mathrm{C}$ above that temperature that causes onset of shivering. This will ensure maximal stimulation of BAT activity. ${ }^{49}$ This type of cooling is called individualised cooling protocol. When obese subjects are studied, air cooling even up to $9^{\circ} \mathrm{C}$ is not sufficient to maximally stimulate BAT and hence water cooling is recommended as a preferred and promising approach. ${ }^{50}$ Some adverse effects of cooling have been pointed out which may blunt the brown fat response. These include shivering and stimulation of pain sensitive receptors. Care should be taken avoid these responses or make sure that shivering is non-existent or minimal during cold exposure. To evaluate shivering electromyogram can be used. Therefore, this area of cold exposure treatment looks though a natural way, it requires proper design and standardized protocols to optimize the benefits before conclusively pronouncing it as an efficient method. ${ }^{16}$
Exercise and use of nonpungent capsaicin in diet are known to stimulate BAT thermogenesis by enhancing mitochondrial UCP1 production to promote the heat production just like cold exposure. The role of gut microbiome in energy balance reported very recently is very interesting. It has been shown that there is an intimate relationship between the gut flora and BAT thermogenesis. It is possible that the bacteria in the gut flora is affected by the diet and may alter the metabolic functions of the host. Cold exposure in such situations can influence the microbial flora and help losing the extra fat as well as improve the gastrointestinal absorptive functions. ${ }^{51,52}$ Therefore, it appears that several communication pathways linking the brain, skeletal muscle, gut and other organs including the heart and liver involve short-term and long-term signals that may help to balance the energy intake and expenditure. Thus, BAT being a major site for mammalian non-shivering thermogenesis could be a promising target for prevention and treatment of human obesity. $20.22,23,33,36$

\section{Conclusion}

The important strategy for addressing obesity and related problems seems to be reducing total adipose tissue mass which may be achieved by several means. For example, an in-depth understanding of molecular actions of adipokines would certainly provide some ways of dealing with the problem. The major challenges will be to identify all of the secreted proteins by WAT to establish the function of each secreted protein and to assess the pathophysiological consequences of changes in their production. Recent observations of BAT being functional in adult humans provides a rationale for its stimulation to increase energy expenditure through adaptive thermogenesis for an anti-obesity strategy. A large body of data available suggest that targeting endocrine hormones for BAT modulation can yield a positive answer for successful prevention and management of human obesity. Therefore, further understanding of the physiological link between various endocrine/autocrine/paracrine hormones and BAT is necessary for the development of new therapeutic options.

All in all, obesity is a multidimensional metabolic disorder and is rarely cured once it sets in. Hence, long term treatment should be planned with combined therapy that involves behavioural and physiogical approaches for effectiveness. It may be good to avoid pharmacological and surgical approaches in such situations. The scientific world eagerly awaits further advanced studies to document possible metabolic interventions using BAT as a primary target to prevent and manage obesity.

\section{Acknowledgements}

There were no funding sources for the study.

\section{Conflicts of interest}

The author declares no conflict of interest.

\section{References}

1. Maxwell K. Med Magazine. India: Macmillan Publishers Ltd; 2008.

2. Spiegelman BM, Flier JS. Obesity and the regulation of energy balance. Cell. 2001;104(4):531-443.

3. Hall KD, Heymsfield SB, Kemnitz JW, et al. Energy balance and its components: implications for body weight regulation. Am J Clin Nutr. 2012;95(4):989-994.

4. Li MD. Leptin and beyond: an odyssey to the central control of body weight. Yale J Biol Med. 2011;84(1):1-7. 
5. Fischer Posovszky P, Wabitsch M, Hochberg Z. Endocrinology of adipose tissue-An update. Horm Metab Res. 2007;39(5):314-321.

6. Haslam DW, James WP. Obesity. Lancet. 2005;366(9492):1197-1209.

7. Wozniak SE, Gee LL, Wachtel MS, et al. Adipose tissue: the new endocrine organ? A review article. Dig Dis Sci. 2009;54(9):1847-1856.

8. Proença AR, Sertié RA, Oliveira AC, et al. New concepts in white adipose tissue physiology. Braz J Med Biol Res. 2014;47(3):192-205.

9. Qatanani M, Lazar MA. Mechanisms of obesity-associated insulin resistance: many choices on the menu. Genes Dev. 2007;21(12):14431455 .

10. Carmela RB, Calogero C, Giuseppina C. The role of adipose tissue and adipokines in obesity-related inflammatory diseases. Mediators of Inflammation. 2010:19.

11. Sacks H, Symonds ME. Anatomical locations of human brown adipose tissue: functional relevance and implications in obesity and type 2 diabetes. Diabetes. 2013;62(6):1783-1790.

12. Kajimura S, Saito M. A new era in brown adipose tissue biology: molecular control of brown fat development and energy homeostasis. Annu Rev Physiol. 2014;76:225-249.

13. Bartness TJ, Vaughan $\mathrm{CH}$, Song CK. Sympathetic and sensory innervation of brown adipose tissue. Int J Obes (Lond). 2010;34(Supple 1):36S -42S.

14. Cannon B, Nedergaard J. Brown adipose tissue: function and physiological significance. Physiol Rev. 2004;84(1):277-359.

15. Harms M, Seale P. Brown and beige fat: development, function and therapeutic potential. Nat Med. 2013;19(10):1252-1263.

16. van der Lans AA, Wierts R, Vosselman MJ, et al. Cold-activated brown adipose tissue in human adults: methodological issues. Am J Physiol Regul Integr Comp Physiol. 2014;307(2):103R-113R.

17. Nicholls DG, Locke RM. Thermogenic mechanisms in brown fat. Physiol Rev. 1984;64(1):1-64.

18. Saito M, Okamatsu Ogura Y, Matsushita M, et al. High incidence of metabolically active brown adipose tissue in healthy adult humans: effects of cold exposure and adiposity. Diabetes. 2009;58(7):1526-1531.

19. Trayhurn P, Alomar SY. Oxygen deprivation and the cellular response to hypoxia in adipocytes-perspectives on white and brown adipose tissues in obesity. Front Endocrinol (Lausanne). 2015;6:1-19.

20. Lee YH, Jung YS, Choi D. Recent advance in brown adipose physiology and its therapeutic potential. Exp Mol Med. 2014;46:e78.

21. Poher AL, Altirriba J, Veyrat-Durebex C, et al. Brown adipose tissue activity as a target for the treatment of obesity/insulin resistance. Front Physiol. 2015;6:1-4.

22. Zafrir B. Brown adipose tissue: research milestones of a potential player in human energy balance and obesity. Horm Metab Res. 2013;45(11):774-785.

23. Hondares E, Rosell M, Díaz Delfín J, et al. Peroxisome proliferatoractivated receptor $\alpha(\operatorname{PPAR} \alpha)$ induces PPAR $\gamma$ coactivator $1 \alpha(\mathrm{PGC}-1 \alpha)$ gene expression and contributes to thermogenic activation of brown fat: involvement of PRDM16. J Biol Chem. 2011;286(50):43112-43122.

24. Saito M, Yoneshiro T. Capsinoids and related food ingredients activating brown fat thermogenesis and reducing body fat in humans. Curr Opin Lipidol. 2013;24(1):71-77.

25. Modica S, Wolfrum C. Bone morphogenic proteins signaling in adipogenesis and energy homeostasis. Biochim Biophys Acta. 2013;1831(5):915-923.
26. Koncarevic A, Kajimura S, Cornwall Brady M, et al. A novel therapeutic approach to treating obesity through modulation of TGF $\beta$ signaling. Endocrinology. 2012;153(7):3133-3146.

27. Fisher FM, Kleiner S, Douris N, et al. FGF21 regulates PGC-1 $\alpha$ and browning of white adipose tissues in adaptive thermogenesis. Genes Dev. 2012;26:271-281.

28. Beenken A, Mohammadi M. The FGF family: biology, pathophysiology and therapy. Nat Rev Drug Discov. 2009;8(3):235-253.

29. De Matteis R, Lucertini F, Guescini M, et al. Exercise as a new physiological stimulus for brown adipose tissue activity. Nutr Metab Cardiovasc Dis. 2013;23(6):582-590.

30. Ramos HR, Birkenfeld AL, de Bold AJ. Interacting disciplines: cardiac natriuretic peptides and obesity: perspectives from an endocrinologist and a cardiologist. Endocr Connect. 2015;4(3):R25-R36.

31. Elias I, Franckhauser S, Ferré T, et al. Adipose tissue overexpression of vascular endothelial growth factor protects against diet-induced obesity and insulin resistance. Diabetes. 2012;61(7):1801-1813.

32. Trayhurn P, Drevon CA, Eckel J. Secreted proteins from adipose tissue and skeletal muscle-adipokines, myokines and adipose/muscle crosstalk. Arch Physiol Biochem. 2011;117(2):47-56.

33. Butler PW, Mentuccia D, Celi FS. Stimulating brown fat: a potential future therapeutic approach for obesity and insulin resistance? Heart Metab. 2010;48:19-22.

34. Watanabe M, Houten SM, Mataki C, et al. Bile acids induce energy expenditure by promoting intracellular thyroid hormone activation. Nature. 2006;439:484-489.

35. Wadden TA, Webb VL, Moran $\mathrm{CH}$, et al. Lifestyle modification for obesity: new developments in diet, physical activity, and behavior therapy. Circulation. 2012;125(9):1157-1170.

36. Yoneshiro T, Aita S, Matsushita M, et al. Recruited brown adipose tissue as an antiobesity agent in humans. J Clin Invest. 2013;123(8):3404-3408.

37. Cypess AM, Kahn CR. Brown fat as a therapy for obesity and diabetes. Curr Opin Endocrinol Diabetes Obes. 2010;17(2):143-149.

38. Kaplan LM. Pharmacological therapies for obesity. Gastroenterol Clin North Am. 2005;34(1):91-104.

39. Wyatt HR. Update on treatment strategies for obesity. J Clin Endocrinol Metab. 2013;98(4):1299-1306.

40. Schauer PR, Kashyap SR, Wolski K, et al. Bariatric surgery versus intensive medical therapy in obese patients with diabetes. $N$ Engl J Med. 2012;366(17):1567-1576.

41. Gunawardana SC, Piston DW. Reversal of type 1 diabetes in mice by brown adipose tissue transplant. Diabetes. 2012;61(3):674-682.

42. van Marken Lichtenbelt WD, Schrauwen P. Implications of nonshivering thermogenesis for energy balance regulation in humans. Am J Physiol Regul Integr Comp Physiol. 2011;301(2):285R -296R.

43. Seale P, Kajimura S, Spiegelman BM. Transcriptional control of brown adipocyte development and physiological function of mice and men. Genes Dev. 2009;23(7):788-797.

44. Kajimura S, Seale P, Spiegelman BM. Transcriptional control of brown fat development. Cell Metab. 2010;11(4):257-162.

45. Blondin DP, Labbé SM, Turcotte EE, et al. A critical appraisal of brown adipose tissue metabolism in humans. Clin Lipidol. 2015;10(3):259-280.

46. van Marken Lichtenbelt WD, Vanhommering JW, Smulders SM, et al. Cold activated brown adipose tissue in healthy men. $N$ Eng J Med. 2009;360:1500-1508. 
47. Cypess AM, Chen YC, Sze C, et al. Cold bout not sympathomimetics activates human brown adipose tissue in vivo. Proc natl Acad Sci USA. 2012;109(25):10001-10005.

48. Savastano DM, Gorbach AM, Eden HS, et al. Adiposity and human regional body temperature. Am J Clin Nutr. 2009;90(5):1124-1131.

49. van der Lans AA, Hoeks J, Brans B, et al. Cold acclimation recruits human brown fat and increases nonshivering thermogenesis. $\mathrm{J}$ Clin Invest. 2013;123(8):3395-3403.
50. Vijgen GH, Bouvy ND, Yeile GJ, et al. Brown adipose tissue in morbidly obese subjects. PLos one. 2011;6(2):e17247.

51. Rosen ED. Burning fat by bugging the system. $N$ Engl J Med. 2016;374(9):885-887.

52. Yi CX, Tschöp MH. Brain-gut-adipose-tissue communication pathways at a glance. Dis Model Mech. 2012;5(5):583-587. 